\title{
Metabolic and respiratory effects of theophylline in the preterm infant
}

Virgilio P Carnielli, Giovanna Verlato, Franca Benini, Katia Rossi, Monica Cavedagni, Marco Filippone, Eugenio Baraldi, Franco Zacchello

\begin{abstract}
Background-Methylxanthines are often administered to preterm infants for the treatment of apnoea.

Aims-To study the effects of theophylline on energy metabolism, physical activity, and lung mechanics in preterm infants.

Methods-Indirect calorimetry was performed for six hours before and after administration of a bolus of theophylline $(5 \mathrm{mg} / \mathrm{kg})$ in 18 preterm infants while physical activity was recorded with a video camera. Lung mechanics measurements were performed at baseline and 12 and 24 hours after theophylline treatment. Results-Theophylline increased mean (SEM) energy expenditure by 15 (5) $\mathrm{kJ} / \mathrm{kg}$ / day and augmented carbohydrate utilisation from 6.8 to $8.0 \mathrm{~g} / \mathrm{kg} / \mathrm{day}$, but fat oxidation was unchanged. After theophylline treatment, preterm infants had faster respiration, lower transcutaneous $\mathrm{CO}_{2}$, and improved static respiratory compliance without increased physical activity. Conclusions-A bolus of $5 \mathrm{mg} / \mathrm{kg}$ theophylline increased energy expenditure independently of physical activity, increased carbohydrate utilisation, and improved respiratory compliance. The increased energy expenditure could be detrimental to the growth of the preterm infant.
\end{abstract}

(Arch Dis Child Fetal Neonatal Ed 2000;83:F39-F43)

Keywords: theophylline; preterm infant; calorimetry; energy metabolism; lung; apnoea

Methylxanthines are widely used for the treatment of apnoea of prematurity ${ }^{1}$ and as a useful adjunct in weaning from a mechanical ventilator. ${ }^{2}$ Their effect on metabolic processes has been extensively studied in animals as well as in human adults, and, in general, these compounds have been found to increase energy expenditure..$^{3-7}$ Information on the human neonate is scarce and the results are inconsistent. Two studies, which measured short term respiratory gas exchange before and after treatment with theophylline, showed a pronounced rise in oxygen consumption $\left(\mathrm{VO}_{2}\right)$ of about $20-25 \%,{ }^{67}$ but a third study showed no difference in energy expenditure, as measured by the doubly labelled water technique, between theophylline treated and control infants. ${ }^{8}$ Whether the increase in $\mathrm{Vo}_{2}$ in human adults is due to direct stimulation of the intermediary metabolism or is secondary to increased physical activity is not known. In rats, increased physical activity is in part responsible for the increase in energy expenditure induced by theophylline. ${ }^{9}$ No information is available to date for the human infant.

Another important question is what is the effect of theophylline on lung mechanics and the respiratory control system. Methylxanthines have been shown to increase central inspiratory drive activity ${ }^{10}$ and diaphragmatic contractility, ${ }^{11}$ but very little information ${ }^{12}$ is available on their effects on lung mechanics in vivo.

We studied in preterm infants whether theophylline (a) increases energy expenditure, $(b)$ stimulates physical activity, and (c) has beneficial effects on lung mechanics.

\section{Subjects and methods}

SUBJECTS

Infants were recruited in the neonatal intensive care unit of the Department of Paediatrics of the University of Padova, Italy. Patients eligible for the study were free of congenital anomalies, with a gestational age between 31 and 34 weeks, an adequate weight for gestational age, in a stable clinical condition, and not requiring supplemental oxygen. All preterm infants were studied within 72 hours of birth. Theophylline was given for the prevention of apnoea of prematurity as aminophylline (AminomalMalesci, Firenze, Italy) with a loading dose of 5 $\mathrm{mg} / \mathrm{kg}$ intravenously over one to two minutes followed by a maintenance dose of $2 \mathrm{mg} / \mathrm{kg}$ intravenously every 12 hours. The infants were kept in servo controlled incubators set to a skin temperature of $36.2-36.5^{\circ} \mathrm{C}$. The protocol was approved by the ethics committee of the University of Padova, and informed consent was obtained from the parents.

\section{STUDY PROTOCOL}

The study consisted of the continuous measurement of $\mathrm{VO}_{2}$, carbon dioxide production $\left(\mathrm{VCO}_{2}\right)$, physical activity, transcutaneous oxygen, and carbon dioxide tension for six hours before and six hours after the loading dose of theophylline. Respiratory mechanics was measured before theophylline administration and repeated 12 and 48 hours after. Vital signs were also simultaneously and continuously recorded. No changes in fluid therapy or nutrition were allowed during the 12 hour study involving indirect calorimetry, physiological measurements, and physical activity, so the infants received exactly the same nutrition before and after theophylline. All preterm infants during the study period received continuous intragastric feeding. 
Table 1 Respiratory gas exchange data in 18 premature newborn infants before and after the administration of aminophylline

\begin{tabular}{lllll}
\hline & Before & After & Mean difference & $p$ Value \\
\hline $\mathrm{O}_{2}$ consumption $(\mathrm{ml} / \mathrm{min} / \mathrm{kg})$ & 5.77 & 6.25 & $0.47(0.18)$ & $<0.02$ \\
$\mathrm{CO}_{2}$ production $(\mathrm{ml} / \mathrm{min} / \mathrm{kg})$ & 5.08 & 5.66 & $0.57(0.15)$ & $<0.001$ \\
Respiratory quotient & 0.87 & 0.90 & $0.02(0.01)$ & $<0.03$ \\
Energy expenditure $(\mathrm{kJ} / \mathrm{kg} / \mathrm{day})$ & 170 & 185 & $15(5)$ & $<0.02$ \\
Transcutaneous $\mathrm{PO}_{2}(\mathrm{~mm} \mathrm{Hg})$ & 67.8 & 67.2 & $-0.67(2.35)$ & 0.72 \\
Transcutaneous $\mathrm{PCO}_{2}(\mathrm{~mm} \mathrm{Hg})$ & 39.8 & 35.4 & $-4.48(1.06)$ & $<0.02$ \\
\hline
\end{tabular}

Data are expressed as mean (SEM).

INDIRECT CALORIMETRY

$\mathrm{VO}_{2}$ and $\mathrm{VCO}_{2}$ were measured with an open circuit indirect calorimeter (Biomedin, Padova, Italy) with a flow through circuit connected to a head box; $\mathrm{VO}_{2}$ and $\mathrm{VCO}_{2}$ were determined every minute with a spirometer (for measurement of the flow through), a paramagnetic oxygen sensor, and an infrared $\mathrm{CO}_{2}$ analyser. $\mathrm{VO}_{2}$ and $\mathrm{VCO}_{2}$ were expressed in $\mathrm{ml} / \mathrm{min} / \mathrm{kg}$ after conversion to standard temperature pressure dry. The instrument was calibrated with known gas mixtures. A 30 minute butane burning test was performed before the start of each study. In all the studies, the respiratory quotient (RQ) of the butane was within $2 \%$ of the theoretical value. Energy expenditure, net fat oxidation, and glucose utilisation were calculated from $\mathrm{VO}_{2}$ and $\mathrm{VCO}_{2}$, and $\mathrm{RQ}\left(\mathrm{VCO}_{2} /\right.$ $\mathrm{VO}_{2}$ ) with the classical equations of indirect calorimetry. ${ }^{13}$ Protein oxidation was assumed to be similar before and after theophylline treatment, and, given its minor contribution to the calculation of energy expenditure and substrate utilisation, it was ignored. ${ }^{14}$

MEASUREMENT OF PHYSICAL ACTIVITY

Physical activity was continuously monitored and recorded using a video camera. The videotape was seen and reviewed after the study by an experienced observer who was unaware of whether the tape was of the first or second part of the study. Different levels of activity were assigned according to the simplified Bruck's activity scale as described by Freymond et al. ${ }^{15}$ Levels of activity were defined as follows: 0, no body, arm, or leg movement, facial movement present or not with eyes closed or open; 1 , arm or leg movement with eyes closed or open; 2, total body movement with eyes closed or open; 3 , crying.

RESPIRATORY FUNCTION TESTING

Respiratory system compliance, respiratory system resistance, and expiratory time constant were measured immediately before and 12 and 48 hours after the first theophylline dose. The passive expiratory flow-volume technique (single breath occlusion), a modification of the method described in detail by LeSouef et al, ${ }^{16}$ was applied by using a computerised infant pulmonary function device (SensorMedics 2600, Yorba Linda, California, USA). With this method, a slide valve connected to an appropriate sized face mask (Vital Signs, Totowa, New Jersey, USA) briefly occludes the airway at end inspiration, producing relaxation of the respiratory muscles through the Hering-Breuer reflex, as previously described. ${ }^{17}$ The occlusion is then rapidly removed to allow passive expiration through an H Rudolph (Kansas City, Missouri,
Table 2 Percentage of time before and after theophylline administration spent in the different physical activity phases

\begin{tabular}{llll}
\hline Physical activity & Before & After & p Value \\
\hline Level 0 & 74.8 & 75.0 & 0.75 \\
Level 1 & 15.6 & 14.9 & 0.81 \\
Level 2 & 6.4 & 6.5 & 0.70 \\
Level 3 & 2.5 & 3.5 & 0.06
\end{tabular}

Data are expressed as means.

USA) pneumotachograph (Lilly type; linear to 10 litres/min), connected to a Validyne model DP 250-14 differential pressure transducer (linear to $\pm 0.196 \mathrm{kPa}$ ). Airway pressure is measured during the occlusion through a port in the valve system, connected by stiff tubing to a model DP 250-32 differential pressure transducer (Validyne Engineering Corp, Northridge, California, USA). The dead space of the system (valve pneumotachograph) was $2.8 \mathrm{ml}$. No sedation was given to induce quiet sleep in the infants. Behavioral criteria were used to avoid the necessity of taking measurements during active sleep phases. Infants were studied inside the incubators in the supine posture, with the head in the neutral position and the mandible supported.

TRANSCUTANEOUS GAS MEASUREMENTS

Concomitantly to indirect calorimetry and physical activity recording, transcutaneous $\mathrm{PCO}_{2}$ and $\mathrm{PO}_{2}$ (TCM3 Radiometer, Copenhagen, Denmark) were continuously measured. The electrode was heated at $40^{\circ} \mathrm{C}$ and calibrated before each measurement. The sensor was placed in the abdomen, and 20-30 minutes were allowed for stabilisation. Heart rate and respiratory rate were recorded with a neonatal monitor (78834A Hewlett-Packard, Milan, Italy).

BIOCHEMICAL DETERMINATIONS

Blood glucose was measured with a hemoglucotest (Reflolux S, Boehringer-Mannheim, Mannheim, Germany) by heel puncture. Determinations were performed two hours before the administration of theophylline and again two, six, and 12 hours later. Indirect calorimetry and other measurements were stopped from three minutes before to 10 minutes after the heel puncture.

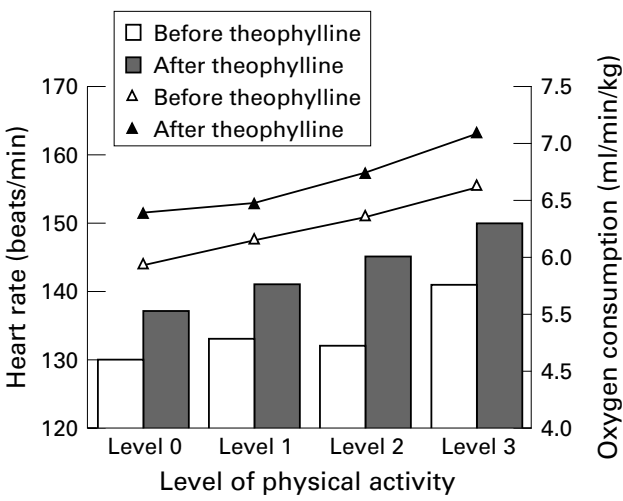

Figure 1 Heart rate (histogram) and oxygen consumption (curves) before and after theophylline administration for each level of physical activity. Heart rate is significantly increased by theophylline $(p<0.001)$ and by the level of physical activity $(p<0.05)$. Oxygen consumption is also increased by theophylline $(p<0.05)$ and physical activity $(p<0.03)$. 
Table 3 Substrate utilisation before and after theophylline administration

\begin{tabular}{llll}
\hline & Before & After & Mean difference \\
\hline $\begin{array}{c}\text { Carbohydrate } \\
\text { utilisation }\end{array}$ & 6.8 & $8.0^{\star}$ & $1.19(0.18)$ \\
Fat oxidation & 1.6 & $1.4 \dagger$ & $-0.21(0.16)$
\end{tabular}

Data are expressed in $\mathrm{g} / \mathrm{kg} /$ day as mean (SEM).

${ }^{\star} \mathrm{p}<0.05, \mathrm{tp}>0.05$ compared with value before treatment.

\section{STATISTICAL ANALYSIS}

Clinical data describing patient to patient variability are given as mean (SD); other data are expressed as mean (SEM). Differences between values obtained before and after theophylline administration were compared using the paired $t$ test. The effect of theophylline treatment on lung mechanics was examined for significance using analysis of variance with subsequent modified $t$ test (Duncan). Differences were considered significant at $\mathrm{p}<0.05$. All calculations were performed using the statistical package SYSTAT, version 5.2 (SYSTAT Inc, Evanston, Illinois, USA).

\section{Results}

All 18 infants enrolled completed the study. Mean (SD) birth weight was $1.76(0.3) \mathrm{kg}$ ranging between 1.13 and 2.47 , gestational age was 32.7 (1.1) weeks (range 31-34), and age at the time of study was 37.9 (25.0) hours (range 15-68). None had any apnoeic episodes during the study period and all had completed the postnatal adaptation period and had constant and normal heart rates and respiratory rates for at least six hours before the beginning of the study. Mean (SEM) energy intake was 136.3 (13.0) $\mathrm{kJ} / \mathrm{kg} /$ day ranging from 101.6 to 302.6 $\mathrm{kJ} / \mathrm{kg} /$ day, with $48.6(7.4) \%$ of the energy intake being administered intravenously as $10 \%$ glucose in water. Table 1 depicts the respiratory exchange data before and after theophylline administration. $\mathrm{VO}_{2}, \mathrm{VCO}_{2}$, and $\mathrm{RQ}$ all rose significantly. The mean (SEM) increase in $\mathrm{VO}_{2}$ was $0.47(0.18) \mathrm{ml} / \mathrm{min} / \mathrm{kg}$ or $8.3 \%$ above the basal consumption. $\mathrm{VCO}_{2}$ rose more sharply from 5.08 to $5.66 \mathrm{ml} / \mathrm{min} / \mathrm{kg}, 11.4 \%$ above the basal value. Mean (SEM) energy expenditure increased by 15 (5) $\mathrm{kJ} / \mathrm{kg} /$ day or $8.8 \%$ of the basal value. The infants spent about $75 \%$ of the study period sleeping both before and after theophylline administration (table 2). No differences were found in the length of time during which arm or leg movements were noted (level 1), total body movement occurred (level 2), or the infant cried (level 3).

Theophylline significantly increased mean (SEM) respiratory rates and heart rates: 49 (3) $v 53$ (2) respirations/min, $\mathrm{p}<0.02$, and 131

Table 4 Effect of theophylline administration on respiratory function in 16 infants

\begin{tabular}{llllll}
\hline & Before & $\begin{array}{l}\text { After 12 } \\
h\end{array}$ & $\begin{array}{l}\text { Mean difference } \\
\text { before-after12 }\end{array}$ & $\begin{array}{l}\text { After } \\
48 h\end{array}$ & $\begin{array}{l}\text { Mean difference } \\
\text { before-after48 } h\end{array}$ \\
\hline $\mathrm{C}_{\mathrm{rs}}(\mathrm{ml} / \mathrm{kPa} / \mathrm{kgPa})$ & 16.6 & $18.3^{\star}$ & $1.73(0.28)$ & $18.8^{\star}$ & $2.23(0.62)$ \\
$\mathrm{R}_{\mathrm{rs}}(\mathrm{kPa} / \mathrm{s})$ & 7.1 & $6.8 \dagger$ & $-0.31(0.09)$ & $6.7 \dagger$ & $-0.43(0.13)$ \\
$\mathrm{TC}(\mathrm{s})$ & 0.23 & $0.26 \dagger$ & $0.02(0.01)$ & $0.24 \dagger$ & $0.02(0.01)$ \\
$\mathrm{TV}(\mathrm{m} / \mathrm{kg})$ & 7.5 & $8.1 \dagger$ & $0.58(0.28)$ & $8.6 \dagger$ & $1.11(0.36)$ \\
\hline
\end{tabular}

Data are expressed as mean (SEM)

${ }^{\star} \mathrm{p}<0.05, \mathrm{tp}>0.05$ compared with value before theophylline treatment.

$\mathrm{C}_{\mathrm{rs}}$, Respiratory system compliance; $\mathrm{R}_{\mathrm{rs}}$, respiratory system resistance; $\mathrm{TC}$, expiratory time constant; TV, tidal volume.
(3) $v 139$ (3) beats/min, $\mathrm{p}<0.001$, before and after theophylline respectively. Heart rate and $\mathrm{VO}_{2}$ were also significantly increased by theophylline ( $\mathrm{p}<0.001$ and $\mathrm{p}<0.05$ respectively) and by physical activity levels $(\mathrm{p}<0.03$ and $\mathrm{p}<0.05$ respectively) (fig 1 ).

Mean (SEM) blood glucose concentration before theophylline administration was 2.60 $(0.19) \mathrm{mmol} / \mathrm{l}$, and it rose to $3.21(0.26), 3.35$ (0.33), and $3.13(0.15) \mathrm{mmol} / \mathrm{l}$ at two, six, and 12 hours respectively after theophylline administration. These values were not significantly higher than the basal determination. Table 3 shows substrate utilisation. Before theophylline, mean (SEM) carbohydrate utilisation was $6.8 \mathrm{~g} / \mathrm{kg} /$ day, and it rose to $8.0 \mathrm{~g} / \mathrm{kg} /$ day $(\mathrm{p}<0.05)$ with a mean difference of 1.19 (0.18). Mean fat oxidation was not altered by theophylline administration: $1.6 v 1.4 \mathrm{~g} / \mathrm{kg} /$ day before and after respectively.

Lung mechanics was studied in 16 of the 18 infants, and table 4 gives the data obtained. Mean (SEM) static respiratory compliance showed a significant improvement from 16.6 to $18.3 \mathrm{ml} / \mathrm{kPa} / \mathrm{kg} 12$ hours after theophylline, with a mean (SEM) difference of 1.73 (0.28), and to $18.8 \mathrm{ml} / \mathrm{kPa} / \mathrm{kg}$ at the 48 hour time point $(\mathrm{p}<0.05)$, with a mean difference of 2.23 (0.62). No significant changes were found in mean respiratory system resistance and expiratory time constant values after the treatment. The mean coefficient of variation was $10 \%$ for respiratory system compliance and $11 \%$ for respiratory system resistance measurements.

\section{Discussion}

We investigated in preterm infants whether theophylline increases energy expenditure, and whether this effect could be related to stimulation of physical activity. We performed indirect calorimetry continuously for 12 hours, and found that a single intravenous dose of theophylline significantly increased energy expenditure by $15 \mathrm{~kJ} / \mathrm{kg} /$ day. This differs from previously published data, which showed either a much greater effect ${ }^{6}$ or no effect. ${ }^{8} \mathrm{VO}_{2}$ rose by $20 \%$ after 48 hours of theophylline treatment in a study by Gerhardt et $a l^{7}$ and by $25 \%$ after 24-48 hours of low dose theophylline in a study by Milsap et al. ${ }^{6}$ Both studies measured short term respiratory gas exchange, and measurements were performed with the infants sleeping. If the daily energy expenditure is calculated from these changes in $\mathrm{VO}_{2}$, theophylline would increase the metabolic rate by about $41.8 \mathrm{~kJ} / \mathrm{kg} /$ day. If these are realistic estimates, theophylline would have a considerable negative effect on the growth of the preterm infant, which could be detected clinically. In our study, theophylline increased energy expenditure by $15 \mathrm{~kJ} / \mathrm{kg} /$ day. Such a difference could still result in a diminished weight gain, which may not be easily detected in the small preterm infant who quite often suffers from several conditions known to affect growth.

At variance with the above studies ${ }^{67}$ and our data, Fjeld et $a l^{8}$ who measured energy expenditure by the doubly labelled water technique, found no difference between preterm infants treated with theophylline and a control 
group. ${ }^{8}$ Several factors may explain this difference. Metabolic adaptation to theophylline may have occurred in the patients of Fjeld et al but not yet in ours. We studied the acute effects of a loading dose of theophylline soon after birth, whereas the infants in the study of Fjeld et al were on a complete oral feed at $2-5$ weeks of age and were probably on a full course of theophylline when studied. Metabolic adaptation to xanthines has been extensively described, and it may result from the inhibition of adenosine receptor binding. ${ }^{18}$ Differences in the calculation of energy expenditure with the doubly labelled water technique may occur when RQs are changing. We found a significantly higher RQ after theophylline administration (table 1). Under these circumstances, if the doubly labelled water technique is used, an underestimation of energy expenditure can be expected in the group with the higher RQthat is, the theophylline treated patients. We cannot prove, however, that the differences in $\mathrm{RQ}$ in our study would persist for long periods, as $\mathrm{VO}_{2}$ and $\mathrm{VCO}_{2}$ measurements were stopped six hours after theophylline administration. We believe that the increase in $\mathrm{VCO}_{2}$ is a reflection of an increased metabolic rate, as $\mathrm{VCO}_{2}$ did not change from 30 minutes after theophylline administration until the end of the study (data not shown). $\mathrm{A} \mathrm{CO}_{2}$ wash out phenomenon resulting from an increased respiratory drive is likely to last for a few minutes only.

The increase in energy expenditure in our patients after theophylline treatment was associated with increased glucose utilisation. Methylxanthines are reported to increase glycogenolysis, ${ }^{19}$ and lipolysis is augmented in adults, ${ }^{20}$ but not in preterm infants. ${ }^{8}$ Increased glycogenolysis may have enhanced carbohydrate utilisation in our patients. We found an increase in plasma glucose after theophylline treatment, as reported by others ${ }^{21-22}$, but the difference did not reach statistical significance. We cannot provide any further biochemical data because blood sampling was limited as we feared that the pain induced by more frequent blood sampling would have influenced energy expenditure and physical activity.

Our second aim was to see if changes in energy expenditure could be related to the effect of theophylline on physical activity. At variance with animal studies, ${ }^{923}$ we did not find that a single dose of theophylline affects physical activity in preterm infants in the first 3 days of life, thus other factors may cause the augmented energy expenditure. Methylxanthines have an effect on the central nervous system and may also be responsible for changes in sleep stages. ${ }^{7}$ Some studies in preterm infants receiving theophylline report an increase in active sleep and wakefulness, ${ }^{24}{ }^{25}$ and there is ample evidence on the effect of sleep stages on energy expenditure. ${ }^{26}{ }^{27}$ We did not perform electroencephalograms, therefore we are not able to quantify clearly the amount of time spent in rapid eye movement sleep before and after theophylline treatment; however, wakefulness was not different. Apart from an increase in rapid eye movement sleep, other mechanisms may be responsible for the changes in energy expenditure, including a direct effect of theophylline at the cellular level and increased work by the respiratory muscles. ${ }^{11}$

After theophylline administration, the patients had higher heart rates, faster respiratory rates, and a decrease in transcutaneous $\mathrm{CO}_{2}$. These results confirm those from other studies. ${ }^{12121928}$ Both caffeine and theophylline produce an increase in minute ventilation, a decrease in $\mathrm{PaCO}_{2}$, and an increase in most indices of neural respiratory drive. Davi et $a l^{10}$ have investigated the effect of theophylline on breathing in newborn infants and found a decreased $\mathrm{CO}_{2}$ threshold and an increased $\mathrm{CO}_{2}$ sensitivity. Gerhardt et al observed a parallel shift in the slope of the $\mathrm{CO}_{2}$ response curve after theophylline administration.

Lung mechanics measurements showed a significant improvement in respiratory compliance after treatment with theophylline. The underlying mechanism may be related to enhanced excursion of the diaphragm ${ }^{11}$ and inspiratory effort. ${ }^{29}$ Both effects may determine recruitment of lung units and improve mechanical effectiveness of the respiratory system. The potentiating effect of theophylline on lung mechanics in vivo shown in our study is consistent with previous findings in animal experiments, ${ }^{30}$ but differs from the study of Gerhardt et $a l^{12}$ who failed to show any improvement in dynamic compliance after theophylline treatment in preterm infants. To evaluate dynamic compliance, it is necessary to monitor oesophageal pressure changes, which are difficult to measure in preterm infants because of chest wall distortion. ${ }^{31}{ }^{32}$ Enhanced diaphragmatic contractility after theophylline administration ${ }^{11}$ worsens chest wall distortion, alters distribution of pleural pressure, and disguises changes in dynamic compliance. We used an occlusion technique which avoids the necessity to estimate pleural pressure. Baseline mean compliance values in this study (16.6 $\mathrm{ml} / \mathrm{kPa} / \mathrm{kg}$ ) are closely similar to those found by Gappa et $a l^{33}(15.4 \mathrm{ml} / \mathrm{kPa} / \mathrm{kg})$ in healthy preterm infants using the same technique and are lower than normative values for full term infants. ${ }^{12} 33$

In conclusion, we have found that theophylline given to slightly preterm infants improved lung compliance, increased energy expenditure by $15 \mathrm{~kJ} / \mathrm{kg} /$ day, and modified substrate utilisation. The rise in energy expenditure was not associated with an increase in physical activity as found in animal studies. We believe that large controlled trials including a long term follow up are mandatory to verify the usefulness and side effects of aminophylline and to ascertain if theophylline treatment results in a clinically significant effect on the growth of the preterm infant. This, in our opinion, is justified by the extensive use of xanthines in the management of preterm infants.

We thank Giuseppe Torresin and his staff for technical support during the validation of the indirect calorimeter.

1 Aranda JV, Grondin D, Sasyniuk BI. Pharmacologic considerations in the therapy of neonatal apnea. Pediatr Clin North Am 1981;28:113-33. 
2 Harris MC, Baugart S, Rooklin AR. Successful extubation of infants with respiratory distress syndrome using aminoof infants with respiratory distress syn

3 Astrup A, Toubro S, Cannon S, Hein P, Breum L, Madsen J. Caffeine: a double-blind, placebo-controlled study of its thermogenic, metabolic, and cardiovascular effects in healthy volunteers. Am f Clin Nutr 1990;51:759-67.

4 Lee TF, Wang LCH. Improving cold tolerance in elderly rats by aminophylline. Life Sci 1985;36:2025-32.

5 Aranda JV, Sasyniuk BI. Respiratory stimulants in the newborn. In: Rubaltelli FF, Granati B, eds. Neonatal therapy: an update. Am

6 Milsap RL, Krauss N, Auld PTH. Oxygen consumption in apneic premature infants after low-dose theophylline. Clin Pharmacol Ther 1980; 28:536-40.

7 Gerhardt T, McCarthy J, Bancalari E. Effect of aminophylline on respiratory center activity and metabolic rate in (1979;63:537-42.

8 Fjeld CR, Cole FS, Bier DM. Energy expenditure, lipolysis, and glucose production in preterm infants treated with theophylline. Pediatr Res 1992;32:693-8.

9 Vonlanthen MG, McCarter RI, Casto DT. Metabolic effects of aminophylline in rats. Am f Physiol 1989;256:R1274-8.

10 Davi MJ, Sankaran K, Simons KJ, Simons FER, Seshia $M M$, Rigatto $\mathrm{H}$. Physiologic changes induced by theophylline in the treatment of apnea in preterm infants. $\mathcal{F}$ Pediatr 1978;92:91-5.

11 Heyman E, Ohlsson A, Heyman Z, Fong K. The effect of aminophylline on the excursion of the diaphragm in preterm neonates. Acta Paediatr Scand 1991;80:308-15.

12 Gerhardt T, McCarthy J, Bancalari E. Aminophylline therapy for idiopathic apnea in premature infants: effects on lung function. Pediatrics 1978;62:801-4.

13 Acheson KJ, Schutz Y, Bessard T, Ravussin E, Jequier E, Flatt JP. Nutritional influences on lipogenesis and thermogenesis after a carbohydrate meal. Am f Physiol 1984;246:E62-70

14 Pineault M, Chessex P, Bisaillon, Brisson G. Total parenteral nutrition in the newborn: impact of the quality
of infused energy on nitrogen metabolism. Am f Clin Nutr of infused en $1988 ; 47: 298$

15 Freymond D, Schutz Y, Decombaz J, Micheli JL, Jequier E. Energy balance physical activity and thermogenic effect of feeding in premature infants. Pediatr Res 1986;20:638-45.

16 LeSouef PN, England SJ, Bryan AC. Passive respiratory mechanics in newborn and children. Am Rev Respir Dis 1984;129:552-6.

17 Baraldi E, Filippone M, Milanesi O, et al. Respiratory mechanics in infants and young children before and after repair of left-to-right shunts. Pediatr Res 1993;34:329-33.

18 Lupica CR, Jarvis MF, Berman RF. Chronic theophylline treatment in vivo increases high affinity adenosine A1 receptor binding and sensitivity to exogenous adenosine in the in vitro hippocampal slice. Brain Res 1991;542:55-62

19 Fredholm BB. On the mechanism of action of theophylline and caffeine. Acta Med Scand 1985;217:149-53.

20 Peters EJ, Klein S, Wolfe R. Effect of short-term fasting on the lipolytic response to theophylline. Am $\mathcal{F}$ Physiol 1991;261:E500-4.

21 Srinivasan G, Singh J, Cattamanchi G, Yeh TF, Pildes RS Plasma glucose changes in preterm infants during oral Plasma glucose changes in preterm infants durit
theophylline therapy. $\mathcal{F}$ Pediatr 1983;103:473-6.

22 Cathcart-Rake WF, Kyner JL, Azarnoff DL. Metabolic responses to plasma concentrations of theophylline. Clin Pharmacol Ther 1979;26:89-95.

23 Denenberg VH, Zeidner LP, Thoman EB, et al. Effects of theophylline on behavioural state development in the newborn rabbit. F Pharmacol Exp Ther 1982;221:604-8.

24 Dietrich J, Krauss AN, Reidenberg M, Drayer DE, Auld PTH. Alterations in state in apneic pre-term infants receiving theophylline. Clin Pharmacol Ther 1978;24:4748.

25 Thoman EB, Holditch Davis D, Raye JR, Philipps AF, Rowe JC, Denenberg VH. Theophylline affects sleep wake development in premature infants. Neuropediatrics 1985;16:13-19.

26 Butte NF, Jensen CL, Moon JK, Glaze DG, Frost JD. Sleep organization and energy expenditure of breast-fed and organization and energy expenditure of breast-

27 Stothers JK, Warner RM. Oxygen consumption and neonatal sleep states. F Physiol 1978;287:435-40.

28 Bucher HU, Wolf M, Keel M, von Siebenthal K, Duc G. Effect of aminophylline on cerebral haemodynamics and oxidative metabolism in premature infants. Eur $\mathcal{F}$ Pediatr 1994;153:123-8.

29 Eichenwald EC, Howell II RG, Leszczynski LE, Stark AR. Theophylline improves coordination of laryngeal abduction and inspiratory effort in premature infants [abstract]. Pediatr Res 1989;25:308A.

30 Oskoui M, Aviado DM, Bellet S. Bronchopulmonary effects of caffeine in the anesthetized dog. Respiration 1970;27:63-7.

31 LeSouef PN, Lopez JM, England SJ, Brian MH, Brian AC. Influence of chest wall distortion on esophageal pressure. 7 Appl Physiol 1983;55:353-8.

32 Gerhardt T, Reifenberg L, Duara S, Bancalari E. Comparison of dynamic and static measurements of respiratory mechanics in infants. F Pediatr 1989;114:120-5.

33 Gappa M, Rabbette PS, Costeloe KL, Stocks J. Assessment of passive respiratory compliance in healthy preterm 1993;15:304-11. 